\title{
Evaluation and assessment of new disposable strip for determination of plasma potassium concentration
}

\author{
I GIBB
}

From the Department of Clinical Biochemistry, Freeman Hospital, Newcastle upon Tyne

SUMMARY Overall laboratory reproducibility for the Ames Seralyzer and plasma potassium test strips was less than $4 \%$ within the plasma reference range; and linearity extended from $2 \cdot 1$ to $10.2 \mathrm{mmol} / \mathrm{l}$. Neither bilirubin nor lipaemia interfered in the analysis and selectivity for potassium over sodium was 450:1. Laboratory comparison with automated flame photometry and an indirect ion selective electrode showed a Seralyzer bias of $+0 \cdot 10( \pm 25 \mathrm{D} 0 \cdot 26)$ and $+0 \cdot 11(0 \cdot 27) \mathrm{mmol} / 1$. Against flame photometry, comparison of analyses by six doctors from a coronary care unit and four nurses from a renal dialysis unit showed smaller positive biases $(0.06$ and $0.02 \mathrm{mmol} / \mathrm{l})$ but substantially larger error ranges $(0.43$ and $0.55 \mathrm{mmol} / \mathrm{l}$, respectively). Some $49 \%$ of the nurses' and $37 \%$ of the doctors' results differed from laboratory values by more than $0.2 \mathrm{mmol} / \mathrm{l}$.

Potassium test strip results proved acceptably comparable and reproducible when produced by an experienced analyst, but greater variability in clinical hands rendered the system unsuitable for precise monitoring of potassium concentration.

The use of a solid phase technique for determining potassium concentration on the Ames Seralyzer reflectance photometer was first described by Charlton et al. ${ }^{1}$ The method has since been further developed and now offers a novel approach to the measurement of plasma potassium that is potentially simple and speedy. This study was undertaken to determine whether the potassium test strip and reflectance unit would yield reproducible results comparable with those of conventional laboratory methods, both when the system was used by an experienced analyst in the laboratory and when used in clinical units by medical and nursing staff.

\section{Material and methods}

REFLECTANCE PHOTOMETER AND POTASSIUM TEST STRIPS

The Seralyzer (Ames Division, Miles Laboratories, USA) is a portable benchtop reflectance photometer controlled by a microprocessor, the principles of which have been described elsewhere. ${ }^{2}$ The instrument may be used for a wide variety of analyses by simply changing the plug-in test module and strips in use.

The reaction on the potassium strip is based on a

Accepted for publication 24 September 1986 colorimetric, ionophore mediated, cation-proton exchange between an aqueous and an organic phase. The reagent area of the disposable strips consists of a paper matrix impregnated with the organic phase and the dried ingredients of the aqueous phase bonded to a bar coded plastic support strip.

When $30 \mu \mathrm{l}$ of a three-fold aqueous plasma dilution is pipetted on to the test area, the buffer ingredients are dissolved and the aqueous phase reconstituted. The potassium selective ionophore 2,3-(naphtho)15-crown-5 in the organic phase mediates the phase transfer of potassium ions. Charge neutrality is maintained by the simultaneous loss of a proton from an indicator dye in the same phase, yielding an absorption peak at $640 \mathrm{~nm}$. The extent of colour development in the reaction is proportional to the concentration of potassium in the sample and is quantitated by monitoring reflectance changes in the strip, the result being displayed in $\mathrm{mmol} / \mathrm{l}$ within 45 seconds.

\section{LABORATORY ASSESSMENT}

The performance of the system was initially evaluated in the laboratory. Intrabatch imprecision was investigated by performing replicate analyses on three human plasma pools and three commercial quality control materials (Sera-Chem normal and abnormal human controls, Fisher Diagnostics, Armtrol Low, 
bovine control serum, Purce Associates Ltd, Antrim, Northern Ireland) using a single calibration and batch of test strips. Interbatch performance over 20 days was checked using the same material, the pooled samples being stored at $-20^{\circ} \mathrm{C}$ and the commercial materials freshly reconstituted daily. During this part of the assessment, the instrument was also recalibrated daily. These performance characteristics of the system were compared with those of routine laboratory methods of emission flame photometry on an SMA6-PLUS (Technicon Instruments) and an indirect reading ion selective electrode on an Astra 8 (Beckman Instruments).

The linear working range of the strip chemistry was checked by analysing proportional mixtures of low and high potassium containing plasma pools, the high pool being spiked with solid potassium chloride. Bias and error associated with potassium strip results were investigated by analysing batches of plasma samples over four weeks using all three methods. Evidence of interference from lipids and bilirubin was sought by similar three instrument comparative analysis of lipaemic and icteric samples. Selectivity of the ionophore for potassium over sodium was quantitated by addition of weighed amounts of sodium chloride to $10 \mathrm{ml}$ volumes of a pooled serum, replicate sodium measurements (SMA flame) being related to those of potassium (Seralyzer) for each addition to determine the sodium concentration required to raise the mean apparent potassium by $0.1 \mathrm{mmol} / 1$. Finally, calibration stability was assessed over three weeks by daily analysis of freshly reconstituted quality control materials, the instrument being calibrated only once at the beginning of the stability study.

\section{CLINICAL ASSESSMENTS}

The clinical trials of plasma potassium determinations were performed in two specialist units within this hospital; a 12 bed renal haemodialysis unit and a 10 bed coronary care unit. Four nurses on the renal dialysis unit and six junior doctors on the coronary care unit were given about 30 minutes of individual "hands-on" instruction with the Seralyzer, and each was also provided with a set of written instructions for subsequent use as required.

\section{Renal dialysis unit study}

The system was used by the nurses for five weeks, during which samples tested were sent to the laboratory for comparative analysis by automated flame photometry. An appropriate control material was provided from the laboratory for regular analysis by the nurses. An acceptable potassium range had been defined for this, and samples from patients were analysed only if the control result was "within range." This material was also analysed daily in the renal dialysis unit by an experienced analyst as an independent check on system performance. About twice each week, as a further check on performance, samples identified only by a code number, which had been previously analysed on the Seralyzer by the nurses, were returned for reanalysis.

\section{Coronary care unit study}

Over 10 weeks doctors analysed blood samples, routinely collected for urea, and electrolyte admission profiles on patients with acute chest pain. Residual plasma samples were sent to the laboratory for comparative analysis. The daily use of a control material with known limits of acceptability and the reanalysis of coded plasma samples was repeated.

\section{Results}

\section{LA BOR A TOR Y}

Table 1 shows the results of intrabatch and interbatch replicate analyses of three human plasma pools and three commercial quality control materials performed

Table 1 Mean (CV\%) comparative interassay and intra-assay imprecisions

\begin{tabular}{|c|c|c|c|c|c|c|}
\hline & \multicolumn{3}{|c|}{ Potassium (mmol/l) } & & & \\
\hline & \multicolumn{3}{|c|}{ Pooled human serum } & \multicolumn{3}{|c|}{ Quality control material } \\
\hline & $A$ & $\boldsymbol{B}$ & $C$ & $x$ & $Y$ & $Z$ \\
\hline $\begin{array}{l}\text { Intra-assay: } \\
\text { Seralyzer }\end{array}$ & $2 \cdot 15(2 \cdot 7)$ & $4 \cdot 64(1 \cdot 5)$ & $6.48(2 \cdot 0)$ & $3 \cdot 00(1 \cdot 7)$ & $4 \cdot 32(2 \cdot 2)$ & $6 \cdot 22(1 \cdot 2)$ \\
\hline SMA & $2 \cdot 21(2 \cdot 2)$ & $4.45(1 \cdot 2)$ & $6.61(0.8)$ & $2 \cdot 78(1 \cdot 5)$ & $4 \cdot 22(1 \cdot 8)$ & $6 \cdot 29(0 \cdot 5)$ \\
\hline Astra & $2 \cdot 26(1 \cdot 6)$ & $4.47(1 \cdot 1)$ & $6.51(0.6)$ & $2 \cdot 76(1.9)$ & $4 \cdot 13(1 \cdot 2)$ & $6 \cdot 13(0 \cdot 8)$ \\
\hline Seralyzer & $2 \cdot 21(4 \cdot 7)$ & $4 \cdot 65(4 \cdot 0)$ & $6.41(2.5)$ & $3.04(3.6)$ & $4 \cdot 27(2 \cdot 6)$ & $6 \cdot 26(3 \cdot 1)$ \\
\hline SMA & $2 \cdot 31(2 \cdot 7)$ & $4.42(1.4)$ & $6 \cdot 52(1 \cdot 1)$ & $2.69(2.4)$ & $4 \cdot 21(1 \cdot 7)$ & $6 \cdot 31(1 \cdot 6)$ \\
\hline Astra & $2.29(1.9)$ & $4 \cdot 44(1 \cdot 1)$ & $6 \cdot 55(1 \cdot 1)$ & $2 \cdot 82(2 \cdot 5)$ & $4 \cdot 19(1 \cdot 7)$ & $6.25(1.4)$ \\
\hline
\end{tabular}

$\mathrm{n}=20$ in all cases; X: Armtrol low (bovine); Y: Fisher normal Sera-Chem (human); Z: Fisher abnormal Sera-Chem (human). 
Table 2 Differences in results between Seralyzer and SMA flame when used by experienced analyst

\begin{tabular}{llllllllll}
\hline Potassium differences (mmol/l) & & -0.2 & -0.1 & 0 & 0.11 & 0.21 & 0.31 & 0.41 \\
& $>-0.21$ & to & to & to & $\begin{array}{l}\text { to } \\
\text { to }\end{array}$ & $\begin{array}{l}\text { to } \\
\text { to }\end{array}$ \\
Incidence & 2 & -0.11 & -0.01 & 0.1 & 0.2 & 0.3 & 0.5 & 0.5 & 0.5 \\
\hline
\end{tabular}

Table 3 Comparison of results of Seralyzer potassium quality control potassium ( $\mathrm{mmol} / \mathrm{l}$ )

\begin{tabular}{llll}
\hline & \multicolumn{3}{l}{ Potassium $(\mathrm{mmol} / l)$} \\
\cline { 2 - 4 } & \multicolumn{1}{l}{ Mean $(S D)$} & $C V \%$ & $N$ \\
\hline Gilford abnormal: & & & \\
Renal dialysis unit nurses & $6 \cdot 99(0 \cdot 29)$ & $4 \cdot 2$ & 19 \\
Experienced analyst & $7 \cdot 19(0 \cdot 25)$ & 3.4 & 23 \\
Gilford normal: & & & \\
Coronary care unit doctors & $4 \cdot 55(0 \cdot 16)$ & 3.5 & 58 \\
Experienced analyst & $4 \cdot 54(0 \cdot 12)$ & 2.6 & 39 \\
\hline
\end{tabular}

on the Seralyzer and by flame photometric and ion selective electrode techniques. Instrument performances were compared to assess bias and error of the strip method. ${ }^{3}$ Table 2 shows the comparison of the Seralyzer with the SMA flame. A significant correlation was observed between result differences and averages $(r=0.25, \mathrm{n}=142, \mathrm{p}=0.02)$, but progressive truncation of low potassium values yielded a non-significant relation when averages exceeded $2.7 \mathrm{mmol} / \mathrm{l}(\mathrm{r}=0.17, \mathrm{n}=132, \mathrm{p}=0.05)$. The Seralyzer bias for the remaining data was $+0 \cdot 10$ $\mathrm{mmol} / \mathrm{l}$, with an error of $\pm 0.26 \mathrm{mmol} / \mathrm{l}$. A similar pattern was seen when comparing the Seralyzer and the Astra ion selective electrode and truncation at 2.7 $\mathrm{mmol} / \mathrm{l}$ gave a bias of $0.11 \mathrm{mmol} / 1$ with an error of $\pm 0.27 \mathrm{mmol} / \mathrm{l}^{3}$

Proportional mixtures of low and high potassium plasma pools gave a linear response for the potassium strip between 2.1 and $10.2 \mathrm{mmol} / \mathrm{l}$. Comparison of results obtained by analysis of five icteric plasmas (bilirubin up to $300 \mu \mathrm{mol} / \mathrm{l}$ ) and five lipaemic samples (triglycerides up to $10.4 \mathrm{mmol} / \mathrm{l}$ ) showed insignificant differences between the three methods of analysis (one way ANOVA, $p=0.05$ ), and selectivity for potassium over sodium was found to be at least 450:1. A calibration stability study, judged by the consistency of results of analysis of three plasma pools stored at $-20^{\circ} \mathrm{C}$, showed minimal change for up to 15 days. On this basis the instrument was calibrated biweekly or when the batch of test strips in use was changed.

\section{RENAL DIALYSIS UNIT}

The Seralyzer was used by four nurses, and table 3 shows their results for the analysis of the control serum compared with those of an experienced laboratory worker. Forty three samples from patients were analysed by the nurses, and comparison of these results with the SMA flame data in table 4 shows no significant association between method differences and average measured potassium $(r=0.05, n=43$, $\mathrm{p}=0.05$ ). Seralyzer bias was $+0.02 \mathrm{mmol} / \mathrm{l}$ and the error $\pm 0.55 \mathrm{mmol} / \mathrm{l}$. No significant differences between individual operator bias were detected.

One additional result was originally recorded as $>12 \mathrm{mmol} / \mathrm{l}$, but on immediate repeat analysis gave a value of $5.41 \mathrm{mmol} / \mathrm{l}$. The first determination had been performed without appropriate dilution of the plasma, but the error had been immediately apparent to the user.

Fourteen samples previously analysed on the unit with a potassium range of $4 \cdot 10-6 \cdot 10 \mathrm{mmol} / 1$ were returned for analysis as coded unknowns. The resultant paired data gave a coefficient of variation for the replication of $5 \cdot 4 \%$.

\section{CORONARY CARE UNIT}

The system was used by six doctors. Table 3 shows the control serum results. Samples from 69 acute chest pain admissions analysed by the doctors showed a small association between intermethod differences and averages $(r=0.27, n=69, p=0.05$ (table 5)). Overall Seralyzer bias was $+0.06 \mathrm{mmol} / \mathrm{l}$ and the

Table 4 Differences in results between Seralyzer and SMA flame when used by nursing staff

\begin{tabular}{|c|c|c|c|c|c|c|c|c|c|c|c|c|}
\hline $\begin{array}{l}\text { Potassium } \\
\text { differences (mmol/l) } \\
\text { Incidence }\end{array}$ & $\begin{array}{l}>-0.51 \\
1\end{array}$ & $\begin{array}{l}-0.5 \\
\text { to } \\
-0.41 \\
2\end{array}$ & $\begin{array}{l}-0.4 \\
\text { to } \\
-0.31 \\
3\end{array}$ & $\begin{array}{l}-0 \cdot 3 \\
\text { to } \\
-0 \cdot 21 \\
3\end{array}$ & $\begin{array}{l}-0 \cdot 2 \\
\text { to } \\
-0 \cdot 11 \\
6\end{array}$ & $\begin{array}{l}-0.1 \\
\text { to } \\
-0.01 \\
6\end{array}$ & $\begin{array}{l}0 \\
\text { to } \\
0 \cdot 1 \\
3\end{array}$ & $\begin{array}{l}0 \cdot 11 \\
\text { to } \\
0 \cdot 2 \\
6\end{array}$ & $\begin{array}{l}0 \cdot 21 \\
\text { to } \\
0 \cdot 3 \\
5\end{array}$ & $\begin{array}{l}0 \cdot 31 \\
\text { to } \\
0 \cdot 4 \\
5\end{array}$ & $\begin{array}{l}0 \cdot 41 \\
\text { to } \\
0 \cdot 5 \\
2\end{array}$ & $\begin{array}{l}>0.51 \\
1\end{array}$ \\
\hline
\end{tabular}

Table 5 Differences in results between Seralyzer and SMA flame when used by doctors

\begin{tabular}{|c|c|c|c|c|c|c|c|c|c|c|c|}
\hline $\begin{array}{l}\text { Potassium differences } \\
(\mathrm{mmol} / \mathrm{l}) \\
\text { Incidence }\end{array}$ & $\begin{array}{l}>-0.31 \\
3\end{array}$ & $\begin{array}{l}-0 \cdot 3 \\
\text { to } \\
-0 \cdot 21 \\
5\end{array}$ & $\begin{array}{l}-0 \cdot 2 \\
\text { to } \\
-0 \cdot 11 \\
11\end{array}$ & $\begin{array}{l}-0.1 \\
\text { to } \\
9^{-0.01}\end{array}$ & $\begin{array}{l}0 \\
\text { to } \\
0 \cdot 1 \\
11\end{array}$ & $\begin{array}{l}0 \cdot 11 \\
\text { to } \\
0 \cdot 2 \\
7\end{array}$ & $\begin{array}{l}0 \cdot 21 \\
\text { to } \\
0 \cdot 3 \\
15\end{array}$ & $\begin{array}{l}0 \cdot 31 \\
\text { to } \\
0 \cdot 4 \\
4\end{array}$ & $\begin{array}{l}0 \cdot 41 \\
\text { to } \\
0 \cdot 5 \\
3\end{array}$ & $\begin{array}{l}0 \cdot 51 \\
\text { to } \\
0 \cdot 6 \\
0\end{array}$ & $\begin{array}{l}>0.61 \\
1\end{array}$ \\
\hline
\end{tabular}


error $\pm 0.43 \mathrm{mmol} / \mathrm{l}$. Consistent operator bias was evident for only one doctor whose results averaged $0.25 \mathrm{mmol} / 1$ in excess of SMA flame values. A single result from the Seralyzer was recorded as $<2.0$ $\mathrm{mmol} / \mathrm{l}$, but in the laboratory the potassium was found to be $4.5 \mathrm{mmol} / \mathrm{l}$. Subsequent reanalysis of the sample on the Seralyzer as a coded unknown produced a result of $4.61 \mathrm{mmol} / \mathrm{l}$. The initial low result had been obtained when an incorrect dilution had been used.

Seventeen samples previously analysed on the unit with a potassium range of $3 \cdot 28-5 \cdot 50 \mathrm{mmol} / 1$ were returned for analysis as coded unknowns. The resultant paired data gave a coefficient of variation for the replication of $4.8 \%$.

\section{Discussion}

One of the principal considerations, when comparing a new analytical method against routinely used techniques, is that it should have a suitable working range; be free of potential interference from endogenous substances; and be adequately reproducible. The method must also be capable of yielding results with acceptable bias and with a degree of reliability appropriate to specific clinical applications.

The apparent dynamic range of the system was clinically relevant as plasma potassium concentrations below $2 \mathrm{mmol} / \mathrm{l}$ are only rarely found, and concentrations of $10 \mathrm{mmol} / \mathrm{l}$ are most certainly incompatible with human life. A negative bias, however, was noted below $2.7 \mathrm{mmol} / \mathrm{l}$. Neither lipaemia nor icterus caused significant interference with potassium measurement, and the selectivity of the ionophore was sufficient to obviate sodium interference even at the extremes of the pathological range likely to be found in human plasma.

For judging the precision of the method, several criteria are available. Using Tonks's rule, ${ }^{4}$ the allowable limits of error should not exceed a quarter of the reference interval, yielding an acceptable coefficient of variation for this determination of up to $5 \cdot 4 \%$. Alternatively, Barnett ${ }^{5}$ derived medically significant coefficient of variations from a synthesis of opinions of clinicians and laboratory specialists to arrive at a figure of $4 \cdot 2 \%$ for this determination. According to both sets of criteria, reproducibility of strip results in the hands of an experienced analyst in the laboratory was of acceptable proportions. Control analyses performed by the nurses and doctors were also within these limits, but both groups could satisfy only the Tonks's limits for repeat analysis of samples from patients. More rigorous goals for precision have been advocated, ${ }^{6}$ both for serial sample testing in the same subject (coefficient of variation $=3 \%$ ), and for single sample analysis (coefficient of variation $=2 \cdot 5 \%$ ). While these levels of performance were attainable with flame emission and the ion selective electrode, they were not achieved by any of the users of the Seralyzer system.

For all operators, the Seralyzer had an overall positive bias of up to $0.11 \mathrm{mmol} / \mathrm{l}$. This is most likely to reflect differences in the sources of the calibrating materials, which were the respective instrument manufacturers' products. The error seen in Seralyzer results was least in the hands of an experienced analyst, for whom $80 \%$ of the results did not differ from the laboratory value by more than $0.2 \mathrm{mmol} / \mathrm{l}$. For the doctors and nurses alike, however, the error was substantially larger; almost half the nurses' results and over one third of the doctors' results differed from the laboratory value by more than $0.2 \mathrm{mmol} / \mathrm{l}$.

I conclude that the Seralyzer dry reagent strip for plasma potassium determination has been shown to be usable by an experienced analyst; produces results that are both comparable with conventional laboratory techniques and generally sufficiently reliable for clinical use. Plasma potassium determinations performed by clinical staff using the Seralyzer were more variable and, although they might be used to indicate the possible need for therapeutic measures, they could not be used for precise monitoring of such treatment.

I am grateful to Ames Division, Miles Laboratories, UK for the loan of the Seralyzer and for supplying the test strips used in the laboratory assessment. I also acknowledge the willing cooperation of the doctors and nurses who participated in this study, and the advice of Dr D Appleton of the medical statistics department, University of Newcastle upon Tyne.

\section{References}

1 Charlton SC, Fleming RL, Zipp A. Solid phase colorimetric determination of potassium. Clin Chem 1982;28:1857-61.

2 Zipp A. Development of dry reagent chemistry for the clinical laboratory. J Auto Chem 1981;3:71-5.

3 Altman DG, Bland JM. Measurement in medicine: the analysis of method comparison studies. The Statistician 1983;32:307-17.

4 Tonks DB. A study of the accuracy and precision of clinical chemistry determinations in 170 Canadian laboratories. Clin Chem 1963;9:217-23.

5 Barnett RN. Medical significance of laboratory results. Am J Clin Pathol 1968;50:671-6.

6 Proceedings of the Subcommittee on Analytical Goals in Clinical Chemistry. World Association of Societies of Pathology. Analytical goals in clinical chemistry: their relationship to medical care. Am J Clin Pathol 1979;71:624-30.

Requests for reprints to: Mr I Gibb, Principal Biochemist, Department of Clinical Biochemistry, Freeman Hospital, Newcastle upon Tyne, England NE7 7DN. 